\title{
PENGEMBANGAN JARINGAN KOMPUTER UNIVERSITAS ANDI DJEMMA BERDASARKAN PERBANDINGAN PROTOKOL ROUTING STATIK DAN OSPFV2
}

\author{
Muhlis Muhallim ${ }^{1)}$ \\ ${ }^{1)}$ Dosen Program Studi Teknik Informatika, Universitas Andi Djemma, Palopo \\ ${ }^{1)}$ muhlis.dp04@gmail.com
}

\begin{abstract}
Abstrak
Pengembangan jaringan komputer baik itu jaringan lokal maupun jaringan internet pada Universitas Andi Djemma sangat dibutuhkan untuk mendukung keperluan pertukaran data antar fakultas dan universitas dalam administrasi aktivitas mahasiswa. Untuk mendukung pengembangan jaringan tersebut dibutuhkan gambaran jaringan yang akan menghubungkan antar fakultas di Universitas Andi Djemma dengan menerapkan routing statik sebagai routing yang diterapkan sekarang dan routing OSPFv2 sebagai routing protokol perbandingan untuk pengembangan jaringan. Pengembangan jaringan dilakukan dalam bentuk modeling (simulasi) menggunakan GNS3. Jaringan yang menerapkan routing statik dan OSPFv2 dianalisis untuk mengetahui kinerja dari routing protokol tersebut. Parameter QoS delay, throughput, jitter dan packet loss sebagai parameter pengujian. Pengukuran dilakukan dengan mengirimkan PING dengan protokol ICMP. Hasil pengukuran delay dan jitter yang dihasilkan dari pengujian menunjukkan bahwa OSPFv2 dapat memperpendek proses routing dalam pengiriman paket dibandingkan statik. Nilai rata-rata throughput untuk skenario normal pada OSPFv2 sebesar 568,63 Bps dan statik sebesar 565,63 Bps. Untuk skenario sibuk pada OSPFv2 sebesar 514,48 Bps dan statik sebesar 515,11 Bps. Nilai rata-rata untuk packet loss untuk kedua jenis jaringan adalah 0\%. Walaupun perbandingan nilai dari hasil pengujian tidak terlalu signifikan, hal ini menunjukkan bahwa jaringan dengan menerapkan routing OSPFv2 memiliki kinerja yang lebih baik dibandingkan dengan jaringan yang menerapkan routing statik.
\end{abstract}

Kata kunci: Routing Statik, OSPFv2,Quality of Service

\section{PENDAHULUAN}

Pesatnya perkembangan teknologi informasi saat ini menuntut kemajuan dalam berbagai aspek teknologi, salah satunya adalah tersedianya kualitas layanan yang baik dalam suatu jaringan komputer, baik itu berasal dari jaringan lokal maupun melalui jaringan internet. Seiring bertumbuhnya penggunaan jaringan maka tingkat komplesitas yang terbangun di dalamnya akan meningkat, seperti meningkatnya kinerja routing pada jaringan internet. Routing menjadi salah satu bagian terpenting dalam model jaringan konvesional saat ini masih dilakukan secara individual dengan mengacu pada masing-masing vendor penyedia perangkat jaringan. Hal tersebut menyebabkan sebuah jaringan tidak fleksibel terhadap perubahan yang terjadi ( $\mathrm{F}$., $\mathrm{Hu}$, Q. Hao and K. Bao. 2014)

Penggunaan jaringan komputer yang terkoneksi dengan internet diterapkan oleh Universitas Andi Djemma dilaksanakan oleh Fakultas Teknik dalam pembuatan laboratorium komputer serta terhubung dengan Fakultas Kehutanan. Seiring dengan perkembangan kebutuhan oleh masing-masing fakultas di Universitas Andi Djemma yang memerlukan koneksi internet dan adanya sharing data dari setiap fakultas pada Universitas untuk keperluan administrasi, maka perlu dirancang pembuatan jaringan komputer untuk diperluas ke masing-masing fakultas. Perluasan jaringan komputer tentunya akan membawa dampak pada kualitas layanan koneksi internet maupun koneksi pertukaran data yang ada. Jika pada awal pembuatan jaringan komputer koneksi internet yang ada hanya digunakan oleh satu fakultas saja namun kedepannya 
akan digunakan oleh empat fakultas. Kualitas layanan internet setelah adanya perluasan jaringan komputer tersebut tentunya akan berubah jika dibandingkan pada awal pembangunan jaringan komputer yang hanya digunakan oleh satu fakultas saja.

Dengan adanya kondisi tersebut di atas perlu adanya sebuah strategi yang matang dalam melakukan pengembangan jaringan komputer yang ada agar setiap pengguna komputer yang akan menggunakan komputer di dalam jaringan komputer akan mendapatkan akses baik sharing data maupun untuk mengakses data ke internet mendapatkan koneksi yang baik. Dalam pengembangan jaringan LAN tentunya membutuhkan penentuan topologi yang menjelaskan pola penghubung antar komponen-komponen yang berkomunikasi melalui peralatan jaringan. Pemilihan routing protocol yang mengatur cara atau jalannya komunikasi pertukaran informasi yang satu dengan yang lainnya yang nantinya akan membentuk tabel routing(A. A. Jostein, M. E. I. Najoan and P. D. K. Manembu. 2015). Dalam penelitian ini akan membandingkan teknik protocol routing static dimana setiap tujuan yang ingin dicapai dalam router ditentukan oleh administrator (I. Marzuki. 2015) dan OSPFv2 yang merupakan protokol yang akan diterapkan dalam pengembangan jaringan. OSPF versi 2 awalnya didokumentasikan dalam RFC 1247 tetapi kemudian diperbarui oleh RFC 2178 dan kemudian lagi pada RFC 2328(J. T. Moy. 1998). Ini adalah versi berikutnya dari OSPF v1. Ada banyak keterbatasan untuk OSPFv1 yang dapat diatasi dengan OSPFv2. Hal ini digunakan untuk konvergensi cepat dijaringan IPv4 dengan deteksi kesalahan yang akurat(M. Jayakumar, N. R. S. Rekha and B. Bharathi. 2105).

Sebagai salah satu langkah dalam kaitan pengembangan jaringan lokal dan juga untuk memenuhi kebutuhan penggunaan internet, maka diperlukan sebuah hasil pengukuran yang dapat mewakili nilai rata-rata kinerja jaringan routing statik dan OSPFv2 dengan menggunakan parameter QoS (Quality of Service). Dengan adanya pengukuran tersebut, maka nantinya akan dapat dijadikan alat untuk menetukan bagaimana karakteristik dari pengembangan jaringan yang sesuai dengan kebutuhan pengguna pada universitas. Terdapat penelitian menyatakan bahwa Quality of Service merupakan salah satu topik yang sulit dipahami pengguna dan membingungkan dalam konteks jaringan data (P. Ferguson and P. Huston.1998). Namun ada juga yang menyatakan bahwa dengan menggunakan pengukuran aktif atau pengukuran pasif merupakan model pengukuran yang integratif, dimana dengan model pengukuran yang integratif tersebut dapat menjadikan Quality of Service dari jaringan dapat diketahui(W. Sugeng, J. E. Istiyanto, K. Mustofa, A. Ashari. 2015)

Diharapkan dengan penelitian ini, dapat mengetahui perbandingan kinerja routing protokol statik dan OSPFv2 pada desain pengembangan jaringan yang akan diimplemetasikan pada jaringan yang ada di Universitas Andi Djemma dengan menggunakan parameter QoS.

\section{METODOLOGI PENELITIAN}

Penelitian mengenai perancangan pengembangan jaringan komputer di Universitas Andi Djemma dilakukan dalam beberapa tahapan, sebagai berikut:

\section{Studi Literatur}

Pada tahap penelitian ini, data mengenai penelitian ini didapat dengan dua cara, yaitu wawancara dan studi pustaka yang dilakukan dengan mempelajari berbagai buku referensi serta hasil penelitian sebelumnya yang sejenis maupun literatur-literatur pendukung (Sudaryono. 2015) dengan mencari sumber-sumber tertulis, jurnal ilmiah, 
buku, tugas akhir maupun karya ilmiah yang berhubungan dengan topik sebagai referensi untuk menganalisis topik penelitian.

\section{Analisis Kebutuhan}

Analisis kebutuhan merupakan modal dasar dari penelitian mengenai pengembangan jaringan jaringan komputer di Universitas Andi Djemma Palopo. Di dalam analisis kebutuhan akan dilakukan analisis terhadap semua data yang dikumpulkan baik kebutuhan akan perangkat keras muapun perangkat lunak untuk mengetahui kinerja dari routing statik yang diterpakan pada jaringan universitas dan routing OSPFv2 sebagai routing digunakan dalam pengembangan jaringan.

a. Perancangan Pengembangan Jaringan Komputer

Tahapan perancangan merupakan langkah awal dalam fase pembuatan dan atau pengembangan sistem untuk setiap produk sistem. Pada tahpan ini akan dihasilkan desain yang nantinya akan diujikan berdasarkan dua skenario pengujian yaitu pada kondisi jaringan normal dan sibuk.

b. Pemodelan Jaringan Komputer

Pada tahapan ini adalah melakukan modelling jaringan menggunakan simulator GNS3. Tahap modelling jaringan komputer ini dilakukan untuk meminimlisir biaya dan kerusakan yang dapat terjadi pada perangkat kerans jaringan baik disebabkan faktor alam maupun human error.

c. Pengujian

Dalam tahap ini dilakukan pengujian terhadap desain dan konfigurasi jaringan komputer yang dalam tahap modelling jaringan. Pengujian dilakukan dengan mengirimkan paket PING dengan protokol ICMP(A.S., Tanenbaum. 2003) pada tiap titik pengukuran. Selanjutnya dilakukan analisis terhadap hasil pengukuran untuk tiap parameter yang diujikan. Kualitas parameter delay dinilai berdasarkan Tabel 1, paramater jitter berdasarkan Tabel 2 dan paramater packet loss berdasarkan Tabel 3(Tiphon. 1999). Selanjutnya hasil pengukuran diuraikan berdasarkan data saat pengukuran untuk tiap paramater QoS yang diujikan.

\section{Paramater Throughput}

Parameter pengujian QoS yang pertama yang digunakan pada penelitian ini adalah throughput. Throughput yaitu kecepatan (rate) transfer data efektif, yang diukur dalam Bps. Header dalam paket data mengurangi nilai ini. Throughput dapat dihitung dengan melihat jumlah paket yang datang terhadap yang dikirim. Untuk mencari nilai throughput dengan menggunakan persamaan (1):

$$
\text { Throughput }=\frac{\text { Jumlah data yang diterima }}{\text { waktu pengiriman data }}
$$

\section{Parameter Delay}

Delay atau latency adalah berapa lama waktu yang dibutuhkan pesan untuk benarbenar tiba di tujuan dari waktu bit pertama dikirim keluar dari sumbernya. Total delay dapat dihitung dengan menggunakan persamaan (2). Persamaan (4) digunakan untuk menghitung delay rata-rata dari total paket yang terkirim:

Total delay $=\sum$ Waktu paket terima - waktu paket dikirim

Delay rata - rata $=\frac{\text { Total delay }}{\text { Total paket dikirim }}$ 
Kategori delay dari hasil pengukuran dapat dilihat pada Tabel 2.

Tabel 1. Kategori Delay

\begin{tabular}{ll}
\hline \multicolumn{1}{c}{ Katagori latensi } & \multicolumn{1}{c}{ Besar Delay } \\
\hline Sangat Bagus & $<150 \mathrm{~ms}$ \\
\hline Bagus & $150 \mathrm{~ms} \mathrm{~s} / \mathrm{d} 300 \mathrm{~ms}$ \\
\hline Sedang & $300 \mathrm{~ms} \mathrm{~s} / \mathrm{d} 450 \mathrm{~ms}$ \\
\hline Jelek & $>450 \mathrm{~ms}$ \\
\hline
\end{tabular}

\section{Parameter Jitter}

Jitter lazimnya disebut variasi delay, berhubungan erat dengan latency yang menunjukkan banyaknya variasi delay pada transmisi data dijaringan(W. Sugeng, J. E. Istiyanto, K. Mustofa, A. Ashari. 2015). Jitter dapat dihitung dengan menggunakan persamaan (4). Persamaan (5) digunakan untuk mencari total variasi delay.

$$
\text { Jitter }=\frac{\text { Total variasi jitter }}{\text { Total paket yang diterima }}
$$

Total variasi jitter $=$ Delay $-($ rata - ratadelay $)$

Kategori nilai jitter dapat dilihat pada Tabel 2.

Tabel 2. Kategori Jitter

\begin{tabular}{ll}
\hline \multicolumn{1}{c}{ Katagori Jitter } & \multicolumn{1}{c}{ Besar Jitter } \\
\hline Sangat Bagus & $0 \mathrm{~ms}$ \\
\hline Bagus & $0 \mathrm{~ms} \mathrm{~s} / \mathrm{d} \mathrm{75} \mathrm{ms}$ \\
\hline Sedang & $75 \mathrm{~ms} \mathrm{~s} / \mathrm{d} 125 \mathrm{~ms}$ \\
\hline Jelek & $125 \mathrm{~ms} \mathrm{~s} / \mathrm{d} 225 \mathrm{~ms}$ \\
\hline
\end{tabular}

\section{Paramater Packet loss}

Packet loss merupakan banyaknya paket yang gagal untuk mencapai tempat tujuan pada saat paket tersebut dikirim. Ketika packet loss besar maka dapat diketahui bahwa jaringan sedang sibuk atau terjadi overload. Packet loss mempengaruhi kinerja jaringan secara langsung. Persamaan (6) digunakan untuk mencari packet loss:

$$
\text { Packet Loss }=\frac{\text { Paket kirim }- \text { paket terima }}{\text { Paket kirim }} \times 100 \%
$$

Kategori nilai packet loss dapat dilihat pada Tabel 3.

Tabel 3. Kategori Packet loss

\begin{tabular}{ll}
\hline Katagori Degradasi & \multicolumn{1}{c}{ Paket Loss } \\
\hline Sangat Bagus & $0 \%$ \\
\hline Bagus & $3 \%$ \\
\hline Sedang & $15 \%$ \\
\hline Jelek & $25 \%$ \\
\hline
\end{tabular}

Topologi rancangan pengembangan jaringan

Dalam rangka pengembangan jaringan komputer di Universitas Andi Djemma maka perlu adanya sedikit perubahan dari topologi jaringan komputer untuk mempersiapka pengembangan jaringan komputer tersebut. Perubahan pada toplogi jaringan komputer akan berubah dari dua router menjadi empat router yang akan 
dipergunakan di dalam jaringan komputer di Universitas Andi Djemma. Rancangan pengembangan jaringan komputer di Universitas Andi Djemma dapat digambarkan seperti pada Gambar 1.

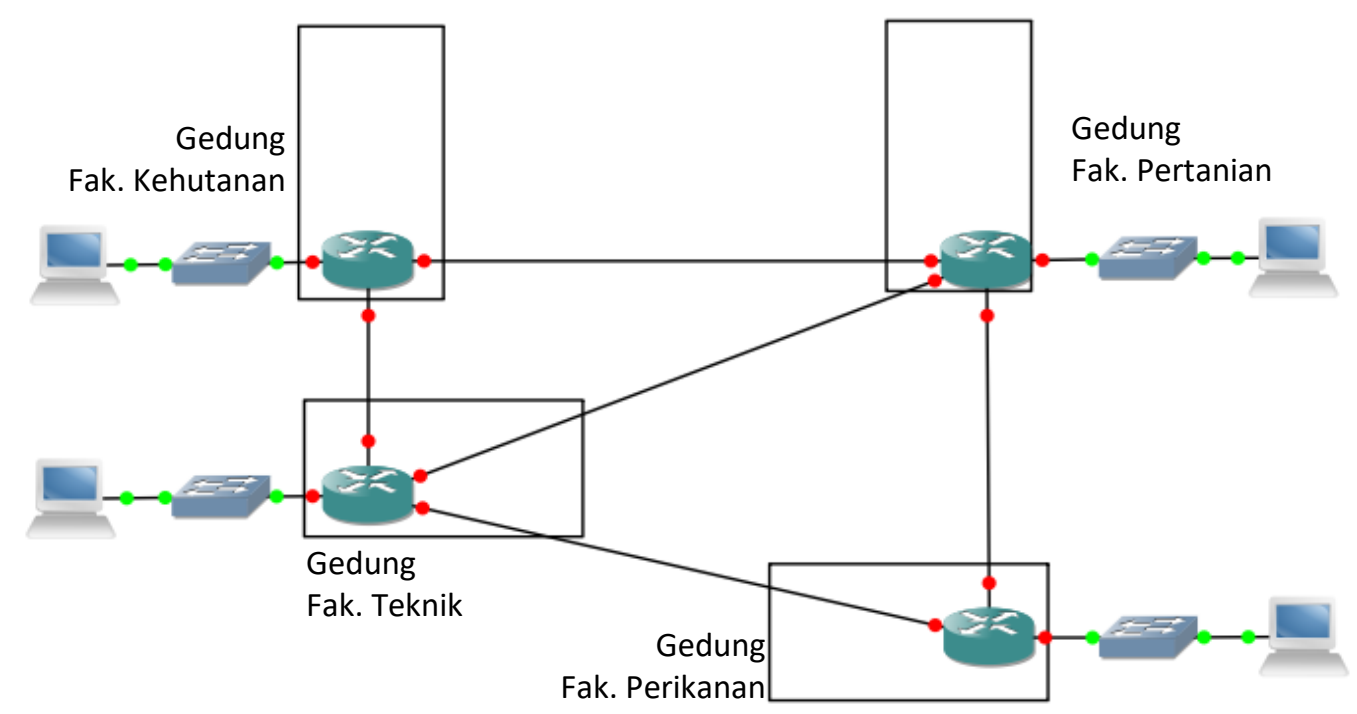

Gambar 1. Rancangan koneksi antar router pengembangan jaringan

\section{HASIL DAN PEMBAHASAN}

\section{Hasil dan Analisis Throughput}

Dalam penelitian ini, nilai throughput didapatkan dari hasil yang diperoleh selama proses pengukuran dengan menggunakan persamaan (1). Hasil pengukuran paramater throughput kemudian di tampilkan dalam dua bentuk, yaitu berdasarkan ukuran data dan hari pengukuran.

a. Hasil pengukuran throughput routing static

Tabel 4 merupakan nilai rata-rata throughput routing statik pada saat pengukuran dengan dua skenario pengujian.

Tabel 4. Rata-rata throughput berdasarkan ukuran data

\begin{tabular}{ccc}
\hline & \multicolumn{2}{c}{ Rata-rata Throughput (Bps) } \\
\cline { 2 - 3 } Ukuran Data (Bytes) & $\begin{array}{c}\text { Skenario } \\
\text { Normal }\end{array}$ & $\begin{array}{c}\text { Skenario } \\
\text { Sibuk }\end{array}$ \\
\hline 100 & 134,91 & 123,60 \\
\hline 200 & 229,81 & 210,85 \\
\hline 300 & 325,00 & 297,68 \\
\hline 400 & 422,06 & 384,64 \\
\hline 500 & 522,75 & 472,90 \\
\hline 600 & 620,08 & 558,37 \\
\hline 700 & 711,06 & 645,88 \\
\hline 800 & 805,23 & 732,73 \\
\hline 900 & 899,81 & 818,63 \\
\hline 1000 & & \\
\hline Rerata & 985,58 & 905,81 \\
\hline & 565,63 & 515,11 \\
\hline
\end{tabular}


Berdasarkan pada Tabel 4, nilai rata-rata throughput baik pada pengujian dengan skenario normal maupun dengan skenario sibuk nilai throughput pada pengukuran ke1 yang mempresentasikan pengujian dengan ukuran data 100 Bytes memiliki nilai throughput yang terendah bila dibandingkan dengan pengukuran dengan data yang lain. Nilai throughput yang didapatkan mengalami peningkatan seiring dengan peningkatan ukuran data yang dikirimkan. Berdasarkan nilai rata-rata throughput pada pengujian dengan skenario jaringan normal maupun pengujian pada kondisi jaringan sibuk, dapat dikatakan bahwa ukuran data yang digunakan dalam pengukuran mempengaruhi nilai throughput.

b. Hasil pengukuran throughput protokol OSPFv2

Hasil pengukuran throughput untuk protokol OSPFv2 dengan pengujian menggunakan dua skenario Tabel 5.

Tabel 5. Rata-rata Throughput Berdasarkan Hari pengukuran

\begin{tabular}{ccc}
\hline \multirow{2}{*}{$\begin{array}{l}\text { Ukuran } \\
(\text { Bytes })\end{array}$} & Data & \multicolumn{2}{c}{ Rata-rata Throughput (Bps) } \\
\cline { 2 - 3 } & $\begin{array}{c}\text { Skenario } \\
\text { Normal }\end{array}$ & $\begin{array}{c}\text { Skenario } \\
\text { Sibuk }\end{array}$ \\
\hline 100 & 135,03 & 124,10 \\
\hline 200 & 230,57 & 210,28 \\
\hline 300 & 328,56 & 297,23 \\
\hline 400 & 421,75 & 385,05 \\
\hline 500 & 522,01 & 471,05 \\
\hline 600 & 617,18 & 558,16 \\
\hline 700 & 714,12 & 644,88 \\
\hline 800 & 807,19 & 730,87 \\
\hline 900 & 905,67 & 817,84 \\
\hline 1000 & & \\
\hline Rata-rata & 1004,24 & 905,41 \\
\hline Berdasa & 568,63 & 514,48 \\
\hline
\end{tabular}

Berdasarkan Tabel 5, pada skenario normal menunjukkan bahwa nilai rata-rata throughput tertinggi terdapat pada ukuran data 1000 bytes (1004,24 Bps) sedangkan nilai terendah terdapat pada ukuran data 100 bytes $(135,03 \mathrm{Bps})$. Nilai rata-rata throughput pada pengujian dengan skenario kedua yaitu pengujian dilakukan pada saat jaringan sibuk. Nilai rata-rata throughput yang didapatkan mengalami peningkatan seiring dengan peningkatan ukuran data yang dikirimkan.

\section{Hasil dan Analisis Delay}

Persamaan (2) dan (3) digunakan untuk mencari nilai delay serta rata-rata delay yang terjadi selama proses pengukuran. Pengujian dilakukan pada routing statik dan OSPFv2 dengan dua skenario pengujian sebagai berikut.

a) Hasil pengukuran delay routing statik

Nilai rata-rata delay yang terjadi selama pengukuran dapat dilihat pada Tabel 6. 
Tabel 6. Rata-rata delay routing statik

\begin{tabular}{cccccc}
\hline & & \multicolumn{2}{c}{ Skenario normal } & \multicolumn{2}{c}{ Skenario sibuk } \\
\cline { 3 - 6 } No. & $\begin{array}{c}\text { data } \\
\text { Bytes })\end{array}$ & $\begin{array}{c}\text { Rata-rata } \\
\text { delay }(\mathrm{ms})\end{array}$ & $\begin{array}{c}\text { Kategori } \\
\text { delay }\end{array}$ & $\begin{array}{c}\text { Rata-rata } \\
\text { delay } \\
(\mathrm{ms})\end{array}$ & $\begin{array}{c}\text { Kategori } \\
\text { delay }\end{array}$ \\
\hline 1 & 100 & 56,94 & Sangat bagus & 131,33 & Sangat bagus \\
\hline 2 & 200 & 56,72 & Sangat bagus & 129,97 & Sangat bagus \\
\hline 3 & 300 & 57,98 & Sangat bagus & 129,77 & Sangat bagus \\
\hline 4 & 400 & 55,59 & Sangat bagus & 130,74 & Sangat bagus \\
\hline 5 & 500 & 45,28 & Sangat bagus & 128,33 & Sangat bagus \\
\hline 6 & 600 & 44,29 & Sangat bagus & 129,10 & Sangat bagus \\
\hline 7 & 700 & 49,10 & Sangat bagus & 130,43 & Sangat bagus \\
\hline 8 & 800 & 49,27 & Sangat bagus & 132,01 & Sangat bagus \\
\hline 9 & 900 & 49,98 & Sangat bagus & 131,94 & Sangat bagus \\
\hline 10 & 1000 & 54,82 & Sangat bagus & 131,18 & Sangat bagus \\
\hline \multicolumn{2}{c}{ Rerata } & $\mathbf{5 2 , 0 0}$ & Sangat bagus & $\mathbf{1 3 0 , 4 8}$ & Sangat bagus \\
\hline
\end{tabular}

Berdasarkan Tabel 6 nilai rata-rata delay tertnggi untuk skenario normal pada paket data ukuran 300 bytes $(57,98 \mathrm{~ms})$ sedangkan nilai terendah terdapat pada paket data ukuran 600 bytes (44,29 ms). Pada skenario dimana kondisi jaringan sedang sibuk, rata-rata delay tertinggi pada data ukuran 800 Bytes dengan nilai 132,01 ms sedangkan nilai terendah terdapat pada paket data ukuran 500 bytes dengan delay 128,33 ms. Perubahan nilai rata-rata delay antara skenario normal dan skenario sibuk sangat signifikan, namun berdasarkan standar delay dari tabel klasifikasi standar TIPHON menunjukkan bahwa semua ukuran paket data masuk kedalam kategori sangat bagus.

b) Hasil pengukuran delay protokol OSPFv2

Tabel 7 merupakan nilai rata-rata delay pengukuran dari jaringan yang menerapkan routing OSPFv2 berserta kategori degradasi menurut standar TIPHON pada Tabel 1.

Tabel 7. Rata-rata Packet Loss Berdasarkan Hari pengukuran

\begin{tabular}{|c|c|c|c|c|c|}
\hline \multirow[b]{2}{*}{ No. } & \multirow{2}{*}{$\begin{array}{c}\text { Ukuran } \\
\text { Data }\end{array}$} & \multicolumn{2}{|c|}{ Skenario normal } & \multicolumn{2}{|c|}{ Skenario sibuk } \\
\hline & & $\begin{array}{c}\text { Rata-rata } \\
\text { delay }(\mathrm{ms})\end{array}$ & $\begin{array}{c}\text { Kategori } \\
\text { delay }\end{array}$ & $\begin{array}{l}\text { Rata-rata } \\
\text { delay }(\mathrm{ms})\end{array}$ & $\begin{array}{c}\text { Kategori } \\
\text { delay }\end{array}$ \\
\hline 1 & 100 & 56,22 & Sangat bagus & 125,42 & Sangat bagus \\
\hline 2 & 200 & 54,98 & Sangat bagus & 129,61 & Sangat bagus \\
\hline 3 & 300 & 49,62 & Sangat bagus & 130,18 & Sangat bagus \\
\hline 4 & 400 & 54,14 & Sangat bagus & 128,99 & Sangat bagus \\
\hline 5 & 500 & 45,20 & Sangat bagus & 129,27 & Sangat bagus \\
\hline 6 & 600 & 46,01 & Sangat bagus & 129,76 & Sangat bagus \\
\hline 7 & 700 & 47,62 & Sangat bagus & 130,89 & Sangat bagus \\
\hline 8 & 800 & 48,49 & Sangat bagus & 130,61 & Sangat bagus \\
\hline 9 & 900 & 46,60 & Sangat bagus & 129,91 & Sangat bagus \\
\hline 10 & 1000 & 45,14 & Sangat bagus & 130,52 & Sangat bagus \\
\hline & erata & 49,40 & Sangat bagus & 129,52 & Sangat bagus \\
\hline
\end{tabular}


Rata-rata delay jaringan routing OSPFv2 skenario dalam kondisi normal, menunjukkan bahwa nilai delay rata-rata tertinggi terdapat pada ukuran data 100 bytes $(56,22 \mathrm{~ms})$ sedangkan nilai terendah terdapat pada ukuran data 1000 bytes $(45,14 \mathrm{~ms})$. Pada pengujian dengan skenario jaringan sedang sibuk menunjukkan nilai rata-rata delay tertinggi pada data ukuran 700 Bytes dengan nilai 130,89 ms sedangkan nilai terendah terdapat pada paket data ukuran 500 bytes sebesar 128,33 ms. Nilai dari rerata delay dari pengujian dengan skenario jaringan normal sebesar 49,40 ms dan skenario sibuk dengan nilai rerata 129,52 ms. Dari nilai rerata tersebut menunjukkan bahwa peningkatan delay sangat signifikan pada pengujian dengan kondisi jaringan sibuk. Namun berdasarkan standar delay dari tabel klasifikasi standar TIPHON menunjukkan bahwa semua ukuran paket data masih masuk kedalam kategori sangat bagus.

\section{Hasil dan Analisis Jitter}

Persamaan (4) dan (5) digunakan untuk mencari nilai jitter serta total variasi jitter yang terjadi selama proses pengukuran. Hasil pengujian parameter jitter pada routing statik dan OSPFv2 disajikan dalam bentuk tabel dengan dua skenario pengujian.

a. Hasil pengukuran jitter routing statik

Nilai rata-rata jitter dari setiap ukuran data yang diukur kemudian dihitung dan dikelompokkan lalu ditampilkan pada Tabel 8 .

Tabel 8. Rata-rata jitter routing statik

\begin{tabular}{cccccc}
\hline & Ukuran & \multicolumn{2}{c}{ Skenario Normal } & \multicolumn{2}{c}{ Skenario Sibuk } \\
\cline { 3 - 6 } No. & $\begin{array}{c}\text { Rata-rata } \\
\text { date })\end{array}$ & $\begin{array}{c}\text { jitter } \\
(\mathrm{ms})\end{array}$ & $\begin{array}{c}\text { Kategori } \\
\text { jitter }\end{array}$ & $\begin{array}{c}\text { Rata-rata } \\
\text { jitter }(\mathrm{ms})\end{array}$ & $\begin{array}{c}\text { Kategori } \\
\text { jitter }\end{array}$ \\
\hline 1 & 100 & 14,06 & Bagus & 24,47 & Bagus \\
\hline 2 & 200 & 12,33 & Bagus & 23,99 & Bagus \\
\hline 3 & 300 & 14,03 & Bagus & 22,92 & Bagus \\
\hline 4 & 400 & 12,05 & Bagus & 22,92 & Bagus \\
\hline 5 & 500 & 7,44 & Bagus & 23,70 & Bagus \\
\hline 6 & 600 & 7,22 & Bagus & 26,23 & Bagus \\
\hline 7 & 700 & 9,64 & Bagus & 28,05 & Bagus \\
\hline 8 & 800 & 8,88 & Bagus & 22,72 & Bagus \\
\hline 9 & 900 & 11,72 & Bagus & 26,38 & Bagus \\
\hline 10 & 1000 & 10,67 & Bagus & 24,78 & Bagus \\
\hline & Rerata & $\mathbf{1 0 , 8 1}$ & Bagus & $\mathbf{2 4 , 6 2}$ & Bagus \\
\hline
\end{tabular}

Nilai rata-rata jitter tertinggi untuk pengujian dengan skenario jaringan normal pada data ukuran 100 Bytes dengan nilai 14,06 ms sedangkan nilai terendah terdapat pada paket data ukuran 600 bytes dengan rata-rata jitter 7,22 ms. Untuk skenario jaringan sibuk menunjukkan bahwa nilai rata-rata jitter tertinggi pada data ukuran 700 Bytes dengan nilai 28,05 ms sedangkan nilai terendah terdapat pada paket data ukuran 800 bytes dengan nilai $22,72 \mathrm{~ms}$. Nilai rata-rata jitter meningkat ketika jaringan sedang sibuk. Namun berdasarkan standar jitter dari tabel klasifikasi standar TIPHON menunjukkan bahwa semua ukuran paket data baik itu skenario normal maupun skenario sibuk masuk kedalam kategori bagus.

b. Hasil pengukuran jitter protokol OSPFv2

Hasil pengukuran jitter diurutkan berdasarkan besarnya paket data yang kirimkan dan ditampilkan nilai rata-rata beserta kategori jitter menurut standar TIPHON selama pengukuran pada Tabel 10. 
Tabel 9. Rata-rata jitter protokol OSPFv2

\begin{tabular}{cccccc}
\hline \multirow{2}{*}{ No. } & $\begin{array}{c}\text { Ukuran } \\
\text { data } \\
\text { Bytes })\end{array}$ & $\begin{array}{c}\text { Rata-rata } \\
\text { jitter }(\mathrm{ms})\end{array}$ & $\begin{array}{c}\text { Kategori } \\
\text { jitter }\end{array}$ & $\begin{array}{c}\text { Rata-rata } \\
\text { jitter } \\
(\mathrm{ms})\end{array}$ & $\begin{array}{c}\text { Kategori } \\
\text { jitter }\end{array}$ \\
\hline 1 & 100 & 13,30 & Bagus & 24,10 & Bagus \\
\hline 2 & 200 & 12,97 & Bagus & 24,95 & Bagus \\
\hline 3 & 300 & 13,51 & Bagus & 24,61 & Bagus \\
\hline 4 & 400 & 14,24 & Bagus & 25,47 & Bagus \\
\hline 5 & 500 & 6,93 & Bagus & 21,78 & Bagus \\
\hline 6 & 600 & 7,72 & Bagus & 22,31 & Bagus \\
\hline 7 & 700 & 7,45 & Bagus & 25,29 & Bagus \\
\hline 8 & 800 & 7,10 & Bagus & 25,50 & Bagus \\
\hline 9 & 900 & 7,23 & Bagus & 24,90 & Bagus \\
\hline 10 & 1000 & 5,93 & Bagus & 24,57 & Bagus \\
\hline \multicolumn{2}{c}{ Rerata } & $\mathbf{9 , 6 4}$ & Bagus & $\mathbf{2 4 , 3 5}$ & Bagus \\
\hline
\end{tabular}

Pada skenario jaringan normal menunjukkan bahwa nilai rata-rata jitter tertinggi pada data ukuran 400 Bytes dengan nilai 14,24 ms sedangkan nilai terendah terdapat pada paket data ukuran 1000 bytes dengan nilai rata-rata jitter 5,93 ms. Pada skenario jaringan sibuk menunjukkan bahwa nilai rata-rata jitter tertinggi pada data ukuran 800 Bytes dengan nilai 25,50 ms sedangkan nilai terendah terdapat pada paket data ukuran 500 bytes dengan jitter 21,78 ms. Peningkatan nilai jitter terlihat jelas ketika jaringan dalam kondisi sibuk, namun berdasarkan standar nilai jitter dari tabel klasifikasi standar TIPHON menunjukkan bahwa semua ukuran paket data masuk kedalam kategori bagus.

\section{Hasil dan Analisis Packet Loss}

Dengan menggunakan persamaan (6), persentase packet loss dapat diketahui selama proses pengukuran. Kemudian packet loss dari routing statik dan OSPFv2 dari hasil pengukuran disajikan pada Tabel 11.

Tabel 10.Rangkuman Hasil Pengukuran

\begin{tabular}{cccccc}
\hline & Ukuran & \multicolumn{2}{c}{ Skenario Normal } & \multicolumn{2}{c}{ Skenario Sibuk } \\
\cline { 3 - 6 } No. & $\begin{array}{c}\text { data } \\
\text { (bytes })\end{array}$ & $\begin{array}{c}\text { Rata-rata } \\
\text { packet loss } \\
(\%)\end{array}$ & $\begin{array}{c}\text { Kategori } \\
\text { packet loss }\end{array}$ & $\begin{array}{c}\text { Rata-rata } \\
\text { packet loss } \\
(\%)\end{array}$ & $\begin{array}{c}\text { Kategori } \\
\text { packet loss }\end{array}$ \\
\hline 1 & 100 & 0 & Sangat Bagus & 0 & Sangat Bagus \\
\hline 2 & 200 & 0 & Sangat Bagus & 0 & Sangat Bagus \\
\hline 3 & 300 & 0 & Sangat Bagus & 0 & Sangat Bagus \\
\hline 4 & 400 & 0 & Sangat Bagus & 0 & Sangat Bagus \\
\hline 5 & 500 & 0 & Sangat Bagus & 0 & Sangat Bagus \\
\hline 6 & 600 & 0 & Sangat Bagus & 0 & Sangat Bagus \\
\hline 7 & 700 & 0 & Sangat Bagus & 0 & Sangat Bagus \\
\hline 8 & 800 & 0 & Sangat Bagus & 0 & Sangat Bagus \\
\hline 9 & 900 & 0 & Sangat Bagus & 0 & Sangat Bagus \\
\hline 10 & 1000 & 0 & Sangat Bagus & 0 & Sangat Bagus \\
\hline \multicolumn{2}{c}{ rerata } & 0 & & & 0 \\
\hline
\end{tabular}


Berdasarkan pada Tabel 11, packet loss jaringan routing statik maupun jaringan OSPFv2, menunjukkan bahwa nilai packet loss dengan pengambilan data dengan mengirimkan paket ICMP melalui aplikasi ping dengan ukuran data 100 bytes sampai 1000 bytes dengan rata-rata $0 \%$. Hasil dari pengujian dengan skenario jaringan normal menunjukkan hasil yang sama pada pengujian dengan skenario jaringan sibuk. Berdasarkan standar THIPON menunjukkan bahwa nilai jitter untuk semua ukuran data masuk dalam kategori sangat bagus. Hal ini menyebabkan pada network transport protokol dapat menyediakan pegiriman paket yang dapat dipercaya. Dalam hal apabila terjadi kehilangan paket, penerima akan meminta retransmission atau pengiriman secara otomatis resends sehingga tidak diperoleh kehilangan paket.

\section{KESIMPULAN}

Berdasarkan hasil penelitian yang telah dilakukan dan dianalisis, maka dapat ditarik kesimpulan sebagai berikut: nilai rata-rata throughput untuk skenario normal pada OSPFv2 sebesar 568,63 Bps dan statik sebesar 565,63 Bps. Untuk skenario sibuk pada OSPFv2 sebesar 514,48 Bps dan statik sebesar 515,11 Bps. Dengan demikian OSPFv2 memiliki throughput yang lebih baik dibandingkan dengan statik. Nilai delay dan jitter yang dihasilkan oleh skenario pengujian menunjukkan bahwa OSPFv2 dapat memperpendek proses routing dalam pengiriman paket dibandingkan jaringan statik. Packet loss yang dihasilkan pada jaringan statik dan OSPFv2 adalah 0\%. Hal ini menunjukkan bahwa apabila terjadi kehilangan paket penerima akan meminta retransmission atau pengiriman secara otomatis resends sehingga tidak diperoleh kehilangan paket.

Berdasarkan dari hasil pergukuran yang telah dilakukan menunjukkan bahwa jaringan dengan menerapkan protokol OSPFv2 sebagai routing protokol yang direkomendasikan dalam pengembangan jaringan komputer.

\section{DAFTAR PUSTAKA}

A. A. Jostein, M. E. I. Najoan and P. D. K. Manembu. (2015). Perancangan Routing Protocol Di Jaringan PT. Kawanua Internetindo. E-journal Teknik Elektro dan Komputer,vol.4,no.4.[online]

Available:https://ejournal.unsrat.ac.id/index.php/elekdankom/article/view/8568 [Accessed: 18-May-2017].

A.S., Tanenbaum. (2003). Computer Networks. 4-th edition, ed: Prentice Hall.

F., Hu, Q. Hao and K. Bao. (2014). A Survey on Software-Defined Network and OpenFlow: From Concept to Implementation. IEEE, vol. 16, no. 4. [online]. Available:http://ieeexplore.ieee.org/abstract/document/6819788/. [Accessed:20-Januari-2017].

I. Marzuki. (2015). Perancangan dan Simulasi Routing Static Berbasis IPV4 Menggunakan RouterCisco.vol.5,no.2.[online].

Available:https://www.upm.ac.id/ejurnal/index.php/energy/article/view/48.

[Accessed: 2-November-2017].

J. T. Moy. (1998). OSPF version 2. RFC 2328. [online].

Available: https://www.ietf.org/rfc/rfc2328.txt.

[Accessed: 20-July-2016].

M. Jayakumar, N. R. S. Rekha and B. Bharathi. (2015). A Comparative study on RIP and OSPF protocols,". [online].

Available:http://ieeexplore.ieee.org/abstract/document/7193275/. 
[Accessed:5-Desember-2016].

P. Ferguson and P. Huston. (1998). Quality of Service Delivering QoS on the Interner and in Corporate Network. , New York:John Willey \& Sons.

Sudaryono. 2015. Metodologi Riset Di Bidang TI. Yogyakarta: ANDI.

Tiphon. (1999). Telecommunications and Internet Protocol Harmonization Over Networks (TIPHON), General aspects of Quality of Service (QoS). DTR/TIPHON-05006 (cb0010cs.PDF),.

W. Sugeng, J. E. Istiyanto, K. Mustofa, A. Ashari. 2015. The Impact of QoS Changes toward Network Performance. International Journal of Computer Networks and Communication Security, no. 2, vol. 3, 48-53. [online].

Available:http://www.ijcncs.org/published/volume3/issue2/p5_3-2.pdf. [Accessed: 10-May-2017]. 